\title{
Chimaerula bonai sp. n. (Cestoda: Dilepididae) from the bare-faced ibis, Phimosus infuscatus (Lichtenstein) (Aves: Threskiornithidae) in Paraguay
}

\author{
Boyko B. Georgiev ${ }^{1}$ and Claude Vaucher ${ }^{2}$ \\ ${ }^{1}$ Central Laboratory of General Ecology, Bulgarian Academy of Sciences, 2 Gagarin Street, 1113 Sofia, Bulgaria; \\ ${ }^{2}$ Muséum d'Histoire Naturelle, P.O. Box 6434, 1211 Geneva 6, Switzerland
}

Key words: Cestoda, Dilepididae, Chimaerula, Phimosus infuscatus, Paraguay

\begin{abstract}
Chimaerula bonai sp. $\mathrm{n}$. is described from the small intestine of Phimosus infuscatus (Lichtenstein) in Paraguay. The new species differs from the other two species of Chimaerula Bona, 1994, i.e., Chimaerula woodlandi (Prudhoe, 1960) and Chimaerula leonovi (Belogurov et Zueva, 1968), mainly by the intermediate number of rostellar hooks (30-34 compared to 4246 in the former and 20-22 in the latter), longer rostellar hooks (31-34 $\mu \mathrm{m}$ versus $26 \mu \mathrm{m}$ and 19-21 $\mu \mathrm{m}$, respectively), shorter cirrus sac (58-82 $\mu \mathrm{m}$ versus 158-201 $\mu \mathrm{m}$ and 134-183 $\mu \mathrm{m}$, respectively) and the absence of rosethorn spines in the cirrus armament. Modifications in the generic diagnosis of Chimaerula are proposed in order to conform it with some peculiarities of the new species (i.e., the relatively small and thin cirrus, the absence of rosethorn spines in its armament and the small cirrus sac).
\end{abstract}

The genus Chimaerula Bona, 1994 was proposed for a dilepidid cestode species parasitising Neotropical aramid birds (Bona 1994). Recent investigations added to it a species from Palaearctic charadriiform hosts (Vasileva et al. 1998). The aim of the present article is to provide a description of a new species of Chimaerula found in a ciconiiform host species in the course of a survey on the helminth parasites of wild birds in Paraguay.

\section{MATERIALS AND METHODS}

Cestodes belonging to the new species were found in the specimens of the bare-faced ibis, Phimosus infuscatus infuscatus (Lichtenstein) captured at the mouth of Rio Aquidaban (Province Concepcion, Paraguay) on 15 October 1988 by an expedition of the Muséum d'Histoire Naturelle, Geneva (collection numbers of the host specimens PY 65606563). The host intestines were opened longitudinally, placed in some water for a few minutes and fixed in hot $4 \%$ neutral formalin. In laboratory conditions, the cestode specimens were removed under stereomicroscope, washed in water and stored in $70 \%$ ethanol. Strobila were stained in Mayer's hydrochloric carmine or iron acetocarmine, dehydrated in ethanol series, cleared in eugenol and mounted in Canada balsam. Some scoleces or entire specimens were mounted in Berlese's medium to facilitate adequate observations on rostellar hooks and cirrus armament. The present description is based on about 30 stained entire specimens and several fragments plus four scoleces and two entire cestodes in Berlese's medium. Type specimens are deposited in the collections of the Muséum d'Histoire Naturelle, Geneva
(MHNG), The Natural History Museum, London (BMNH) and U.S. National Parasite Collection, Beltsville (USNPC).

The measurements of the testes, vas deferens, cirrus sac, vitellarium, ovary, vagina and seminal receptacle are taken from fully developed mature proglottides only.

The metrical and meristic data are presented as the range, the mean in parentheses and the number of measurements or counts taken (n). The measurements are given in $\mu \mathrm{m}$ unless where otherwise stated.

Syntypes of Chimaerula woodlandi (Prudhoe, 1960), i.e., two slides from BMNH 1966.1.13.43-48, and specimens of Chimaerula leonovi (Belogurov et Zueva, 1968) from Charadrius alexandrinus L. from Bulgaria (described recently by Vasileva et al. 1998) were used as a comparative material.

\section{RESULTS}

Chimaerula bonai sp. $\mathrm{n}$.

Figs. 1-8

Description: All developed specimens studied terminate with pregravid proglottides. Strobila minute, 8001,360 $(994, \mathrm{n}=20)$ long, consisting of 5-8 $(6.4, \mathrm{n}=21)$ proglottides (Figs. 1, 2); only one pregravid proglottis per strobila. Maximum width at last proglottides, 210$375(282, n=22)$; in one case, last mature proglottis wider than terminating (pregravid) proglottis. Proglottides craspedote, mature almost as wide as long, pregravid proglottides usually longer than wide.

Scolex (Fig. 3) triangular, with maximum width at level of suckers, 138-225 $(174, \mathrm{n}=29)$ in diameter; its anterior part may protrude. Suckers rounded, with weakly to moderately developed musculature, $73-98$ $(82, n=69)$ in diameter. Rostellum retractable, highly 

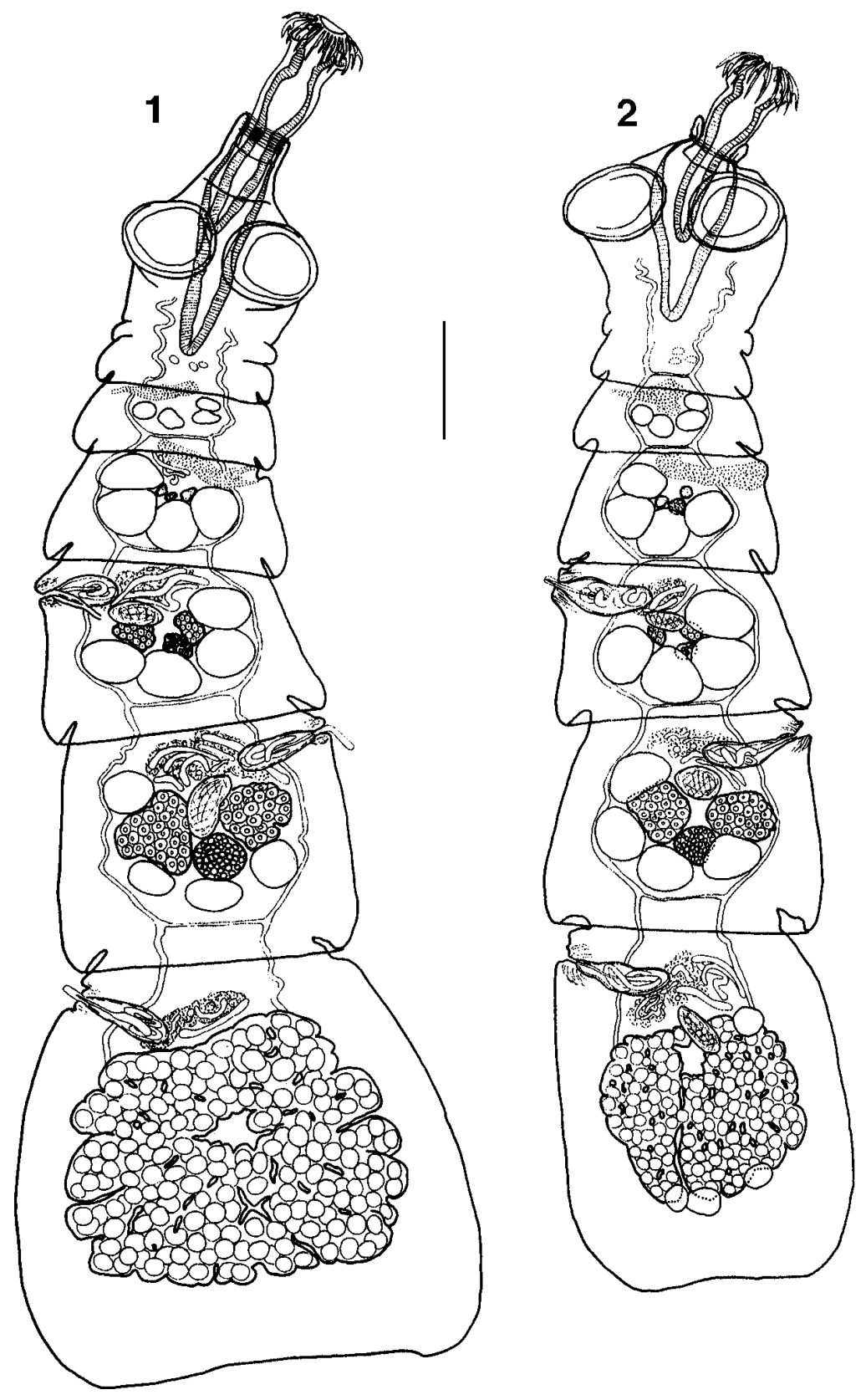

Figs. 1, 2. Chimaerula bonai sp. n., general view. Note the rapid maturation which makes it impossible to observe all the gradual developmental stages of proglottides in a single strobila. Fig. 1. Holotype. Fig. 2. Another specimen demonstrating a different shape of the terminating proglottis. Scale bar $=100 \mu \mathrm{m}$.

protrusible, very long, with strong circular musculature of walls; consists of wide, subglobular pad bearing hooks and long stem with tapering posterior end; anterior surface of pad slightly concave (forming small anterior depression) or everted (forming subglobular elevation); entire length of rostellum 165-215 (194, $\mathrm{n}=14)$, maximum width at anterior pad 53-68 (61, $\mathrm{n}=21$ ); rostellum often folded within rostellar pouch; in few cases, rostellum contracted and then stem slightly wider than apical muscular pad: e.g., diameter of pad
45, diameter of stem 50. Intensely stained cells present within rostellum, connected with longitudinally arranged thin canal-like structures directed to anterior pad; glandular syncytium not observed within rostellum. Rostellar pouch highly elongate, with thick muscular wall, reaching far posterior beyond suckers, entering first or second proglottis, $148-215 \times 48-80(182 \times 61$, n $=24)$. Narrow external cavity with variable depth formed in anterior part of rostellar pouch around rostellum when not fully protruded (Fig. 3). Few intensely 


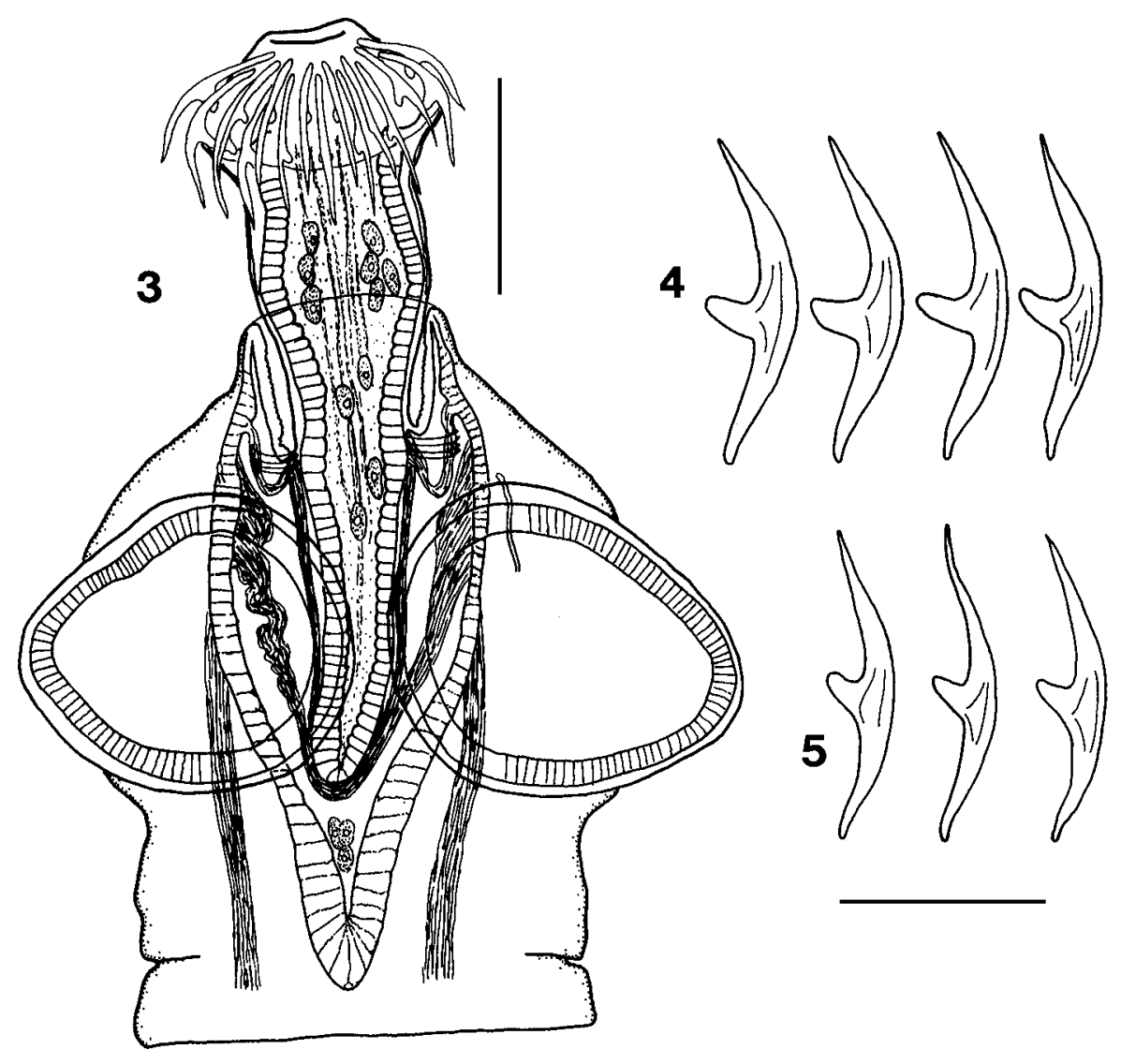

Figs. 3-5. Chimaerula bonai sp. n. Fig. 3. Scolex. Fig. 4. Anterior rostellar hooks. Fig. 5. Posterior rostellar hooks. Scale bars: Fig. $3=50 \mu \mathrm{m}$; Figs. $4,5=20 \mu \mathrm{m}$.

stained cells present in rostellar pouch, situated posteriorly to rostellum. Muscular elements in rostellar pouch (in addition to walls of pouch and rostellum): (1) small muscular bundles attached to bottom of anterior external cavity (and to rostellum at nearly half of its length) and to walls of rostellar pouch; (2) radially arranged fibres situated obliquely, attached to walls of rostellar pouch and surrounding posterior end of rostellum; (3) longitudinal fibres connecting posterior end of rostellum with bottom of anterior external cavity and running along walls of posterior half of rostellum (clearly seen in some scoleces only). Anterior end of longitudinal strobilar musculature attached at about middle of rostellar pouch. Rostellar hooks $30(\mathrm{n}=8), 32$ $(n=13)$ or $34(n=3)$ in number, arranged in two regular rows; blade and handle of almost equal length; anterior and posterior hooks with different shape. Anterior hooks 33-34 (33.4, $\mathrm{n}=6)$ long; guard almost rectangular to axis of handle (Fig. 4). Posterior hooks 31-33 (31.8, $\mathrm{n}=4)$ long; guard forming angle more than $90^{\circ}$ to axis of handle (Fig. 5). Both anterior and posterior hooks with handle tapering to its end and often with blade bent forward.
Strobila protandrous. Genital pores regularly alternating, situated far anterior. Genital atrium may form slightly expressed genital papilla; provided with radial muscular fibres; glandular elements not seen in its walls. Genital ducts dorsal to osmoregulatory canals. Ventral osmoregulatory canals $4-8(\mathrm{n}=8)$ wide, with transverse anastomosis along posterior margin of each proglottis. Dorsal osmoregulatory canals 2-4 $(n=8)$.

Testes 4 in number, 3 forming arch near posterior proglottis margin, one situated antiporally at level of anterior margin of ovary (Fig. 6); diameter 43-63 (51, n $=42$ ). External vas deferens highly coiled, clearly divided into "prostate" and "aprostate" parts; "prostate" part with diameter of lumen 5-8 $(7, n=21)$, covered by intensely stained cells forming compact body, usually overlapping cirrus sac, near anterior proglottis margin; "aprostate" part with diameter of lumen 5-11 (8, n = 21 ), forming numerous coils antiporally and posteriorly to cirrus sac and "prostate" part of vas deferens, often reaching in posterior direction to level of seminal receptacle and ovary. Cirrus sac (Figs. 7, 8) elliptical, crossing poral osmoregulatory canals and rarely extending to midline of proglottis; $58-82(69, \mathrm{n}=20)$ 


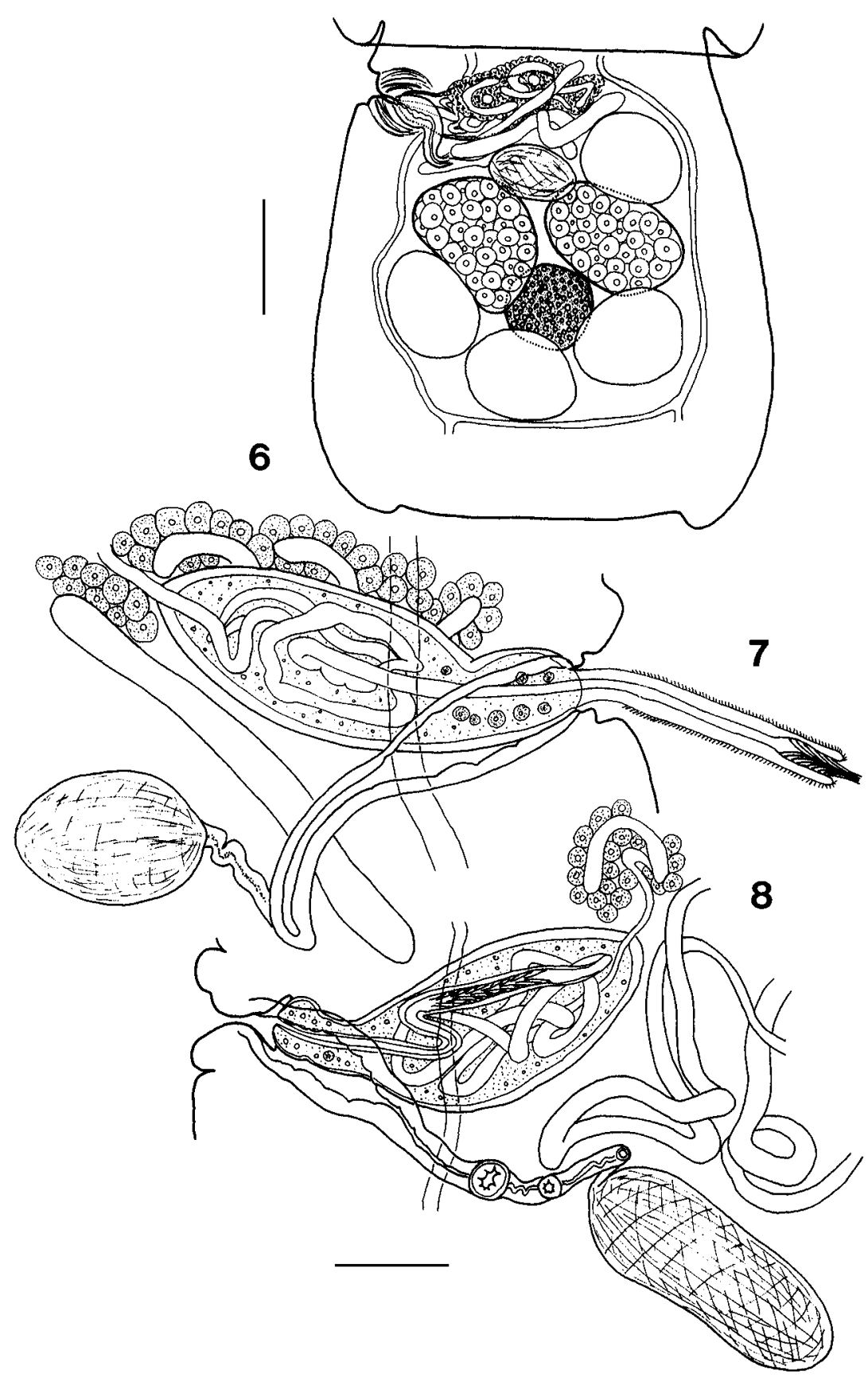

Figs. 6-8. Chimaerula bonai sp. n. Fig. 6. Mature proglottis. Fig. 7. Genital ducts in a mature proglottis (with almost entirely evaginated cirrus). Fig. 8. Genital ducts in a postmature proglottis. Scale bars: Fig. $6=50 \mu \mathrm{m}$; Figs. 7, $8=20 \mu \mathrm{m}$.

long and 23-34 $(27, \mathrm{n}=20)$ wide. Internal vas deferens highly coiled. Evaginated cirrus 6-7 $(\mathrm{n}=8)$ in diameter, cylindrical, armed with numerous tiny needle-shaped spines with length less than $1 \mu \mathrm{m}$; its end provided with bundle (about 15 long) of very delicate bristles (Fig. 7).

Vitellarium compact, rounded (rarely slightly irregular), with diameter 34-45 (40, $\mathrm{n}=19)$, central. Ovary two-winged, each wing rounded, compact or slightly lobed; diameter of wings 48-80 $(58, \mathrm{n}=21)$; no isthmus clearly seen between two wings. Mehlis' gland not observed. Seminal receptacle oval, $36-57 \times 21-31$ $(46 \times 25, \mathrm{n}=19)$. Vagina opens dorsally to male pore; part of it often dorsal to cirrus sac; distal part wide and robust, with external diameter 14-23 $(18, \mathrm{n}=19)$ and diameter of lumen 7-14 $(10, \mathrm{n}=19)$; vaginal wall thick, apparently without glandular elements (Figs. 7, 8). Uterus sacciform, with lobed margins overlapping ventral osmoregulatory canals. Developing eggs (shells not formed) rounded, containing underdeveloped embryonic hooks. 
T у p e h o s t: Phimosus infuscatus infuscatus (Lichtenstein, 1823) (Aves, Ciconiiformes, Threskiornithidae).

Site of infection: Small intestine.

Preva le n c e: 4 birds infected / 4 examined.

Ty p e lo c a 1 it y: The mouth of Rio Aquidaban, Province Concepción, Paraguay.

H o 1 o t y p e : MHNG INVE 27918 (1 slide).

P a r a t y p e s : MHNG INVE 27920-27923 (16 slides); BMNH 1999.12.3.1-4 (4 slides); USNPC 89416 (4 slides).

E t y m o 1 o g y : The new species is named after Professor F.V. Bona, Università di Torino, Italy, in recognition of his immense contribution to the systematics of the cestode family Dilepididae.

\section{DISCUSSION}

Cestodes of the family Dilepididae have been reported from threskiornithid birds from various geographical regions (for surveys see Bona 1975, Ryzhikov et al. 1985). However, there are no species among these records with characters similar to those of the cestodes described above.

Following the key to the genera of the family Dilepididae (see Bona 1994), the present cestodes closely resemble the genus Chimaerula. The description of the new species corresponds to the diagnosis of the latter genus, both as proposed by Bona (1994) or modified by Vasileva et al. (1998), in numerous morphological details. These are the very small strobila, the highly muscular and weakly glandular rostellar apparatus, the very long rostellar pouch reaching far posterior beyond the suckers, the rostellar hooks arranged in two regular rows, the regular alternation of the genital pores, the dorsal position of genital ducts to osmoregulatory canals, the thick-walled vagina opening dorsally to the male orifice, the clearly two-winged compact ovary, the small and compact vitellarium, the small and constant number of testes (4), the cirrus provided with a terminal bunch of fine bristles and the sacciform uterus. A few characters of the new species do not fit to the generic diagnosis. These are the relatively small and thin cirrus (versus "cirrus very long, strong", see Vasileva et al. 1998), the absence of rosethorn spines in its armament (versus "armed (mainly or exclusively) with rosethorn spines of different size") and the smaller cirrus sac (versus "cirrus sac very large, long"). We believe that these distinctions reflect rather the differences between the species of Chimaerula and do not interfere with the allocation of the new species in this genus. Therefore, we propose further modifications in the generic diagnosis, relative to the three characters mentioned, in order to conform it to the morphology of Chimaerula bonai.

Two species have been placed into the genus Chimaerula prior to the present description: $C$. woodlandi (Prudhoe, 1960) Bona, 1994 (type species), a parasite of Aramis guarauna (L.) (Gruiformes, Aramidae) in Brazil (for morphological data see
Prudhoe 1960, Bona 1994, Vasileva et al. 1998), and $C$. leonovi (Belogurov et Zueva, 1968) Vasileva, Georgiev et Genov, 1998, from Palaearctic Charadrius spp. (Charadriiformes, Charadriidae) (see Belogurov and Zueva 1968, Vasileva et al. 1998). C. bonai is characterised by an intermediate number of rostellar hooks (30-34) between those of $C$. woodlandi (42-46) and of $C$. leonovi (20-22). Its hooks are longer than those of its congeners: $33-34 \mu \mathrm{m}$ and $31-33 \mu \mathrm{m}$ for anterior and posterior rows, respectively, compared to $26 \mu \mathrm{m}$ and $26 \mu \mathrm{m}$ for $C$. woodlandi, and $20-21 \mu \mathrm{m}$ and $19-21 \mu \mathrm{m}$ for $C$. leonovi. The cirrus sac of the new species is considerably shorter than those of the other two species (58-82 $\mu \mathrm{m}$ versus $158-201 \mu \mathrm{m}$ in $C$. woodlandi and 134-183 $\mu \mathrm{m}$ in C. leonovi). A very characteristic feature of the new species is the absence of rosethorn spines in its cirrus armament. In contrast, all the spines of the cirrus armament of $C$. leonovi are rosethorn, and $C$. woodlandi has both rosethorn and needle-shaped spines.

The new species can be distinguished from $C$. leonovi also by the shape of the scolex, which has a peculiar campanulate shape in the latter species. The shape of the anterior hooks of $C$. leonovi differs essentially from that of its posterior hooks: the anterior hooks have a straight handle and a relatively small guard at an angle of c. $45^{\circ}$ to the hook axis while the posterior hooks are with a curved handle and a relatively large guard which is almost parallel to the hook axis (see figures 4 and 5 of Vasileva et al. 1998). In contrast, the anterior and posterior hooks of $C$. bonai, although different from one another, both have a rather small guard and an almost straight handle (Figs. 4, 5). $C$. bonai and C. leonovi have also different arrangements of their testes: the former is characterised with one antero-antiporal and three post-ovarian testes while the testes form a compact post-ovarian arch in the latter.

A further substantial difference between $C$. woodlandi and $C$. bonai is the structure of the vagina. This organ is very long and convoluted in the former and rather short and not convoluted in the latter species.

All these differences make the cestodes described clearly distinct from the previously known species of the genus Chimaerula. On this basis, we recognise them as a new species.

Acknowledgements. We are grateful to Professor F.V. Bona (Università di Torino) and to an anonymous reviewer for useful comments on the manuscript, and to Mrs. E.A. Harris (The Natural History Museum, London) for lending syntypes of Chimaerula woodlandi. We also thank the Ministry of Agriculture and Livestock of Paraguay for providing facilities during the field work and the members of the expedition for collecting specimens described (C. Dlouhy, F. Baud, T. Jaccoud and C. Wyler). The senior author is grateful to the Muséum d'Histoire Naturelle, Geneva, for providing a research grant, and to C. Vaucher, A. de Chambrier and the other members of the Department of Invertebrates of the Muséum for their hospitality. 


\section{REFERENCES}

BELOGUROV O.I., ZUEVA L.S. 1968: Two new species of cestodes from charadriiform birds in the Far East. Soobshch. Dal'nevost. Fil. Imeni V.L. Komarova Akad. Nauk SSSR 25: 11-17. (In Russian.)

BONA F.V. 1975: Etude critique et taxonomique des Dilepididae Fuhrm., 1907 (Cestoda) parasites des Ciconiiformes. Considérations sur la spécificité et la spéciation. Monit. Zool. Ital., N.S., Monogr. 1, xii+750 pp.

BONA F.V. 1994: Family Dilepididae Railliet \& Henry, 1909. In: L.F. Khalil, A. Jones and R.A. Bray (Eds.), Keys to the Cestode Parasites of Vertebrates. CAB International, Wallingford (U.K.), pp. 443-554.
PRUDHOE S. 1960: On two new parasitic worms from Brazil. In: Libro Homenaje al Doctor Eduardo Caballero y Caballero. Editorial Politecnica, Mexico, pp. 415-421.

RYZHIKOV K.M., RYŠAVÝ B., KHOKHLOVA I.G., TOLKACHEVA L.M., KORNYUSHIN V.V. 1985: Helminths of the Fish-eating Birds of the Palaearctic Region. Volume II. Cestoda and Acanthocephales. Academia, Prague, $411 \mathrm{pp}$.

VASILEVA G.P., GEORGIEV B.B., GENOV T. 1998: Redescription of Chimaerula leonovi (Belogurov \& Zueva, 1968) n. comb. (Cestoda, Dilepididae). Syst. Parasitol. 40: 229-235.

Accepted 11 May 2000 